\title{
RBEP
}

\section{Institucionalização da formação docente: análise de um programa de desenvolvimento profissional}

\author{
Amanda Rezende Costa Xavier ${ }^{\mathrm{I}, \text { II }}$ \\ Michelle Cristine da Silva Toti ${ }^{\text {III, IV }}$ \\ Maria Antonia Ramos de Azevedov, vi
}

http://dx.doi.org/10.24109/2176-6681.rbep.98i249.2830

\section{Resumo}

Este estudo tem como objetivo principal analisar, com base na literatura discutida, a institucionalização de um programa de desenvolvimento profissional de uma universidade federal brasileira, com vistas a identificar seu nível de consolidação, bem como a concepção dos docentes sobre ele. Adotou-se como metodologia a pesquisa qualitativa e foram utilizadas, para coleta de dados, a análise documental e a aplicação de questionário estruturado aos docentes participantes do programa. O referencial teórico que embasa a análise está pautado nos estudos da pedagogia universitária, especialmente de Cunha, Masetto, Morgado. Foi possível inferir que os documentos institucionais analisados reforçam a visão do programa de formação docente apenas como uma exigência legal para aprovação no estágio probatório, destinado, dessa forma, aos professores ingressantes. Verifica-se, ainda, maior interesse docente nas questões ligadas aos aspectos práticos e/ou burocráticos da docência (uso de sistemas acadêmicos, trâmites legais) em detrimento dos saberes específicos da atuação docente. No entanto, não podemos desconsiderar que a experiência analisada retrata um programa relativamente jovem, com apenas dez anos de existência, e que, frente às alterações que já experimentou, acreditamos haver uma preocupação em aprimorar o programa de formação pedagógica e de desenvolvimento profissional docente.

Palavras-chave: formação docente; desenvolvimento profissional; assessoria pedagógica. 


\section{Abstract \\ Institutionalization of teacher education: analysis of a professional development program}

Based on the discussed literature, this study has the main goal of analyzing the institutionalization of a professional development program in a Brazilian public university. It aims at identifying the level of the program's consolidation and also the opinion that participant teachers have about it. The methodology applied was qualitative research. Document analysis and structured survey were also applied to raise data from teachers participating in the program. The theoretical referential is underpinned by university pedagogy studies, in particular, those by Cunha, Masetto, Morgado. It was possible to infer that the institutional documents analyzed reinforce the image of the teacher training program as a mere legal formality in the path for approval in the supervised traineeship and, as such, a program aimed at newcomers only. The study also demonstrates an increasing interest in issues related to practical and/or bureaucratic aspects of teaching (use of academic systems, legal procedures) over the specific knowledge related to teaching practice. However, the experience analyzed portrays a fairly new program, with no more than ten years. Considering the changes the program has already been through, there is the interest to improve the pedagogical training program and the teacher's professional development program.

Keywords: teacher education; professional development; pedagogical support.

\section{Introdução}

Historicamente, a universidade foi construída sob um modelo curricular no qual o processo de ensino consistia em transmitir os conhecimentos e as experiências profissionais. Os professores universitários eram, portanto, pessoas com sucesso em sua área profissional, pessoas que sabiam fazer o que teriam que ensinar. O objetivo do processo de ensino universitário era conduzir os alunos a saberem fazer com o mesmo sucesso de seus professores (Masetto, 1998).

Esse modelo ainda é encontrado na universidade contemporânea. Trata-se de uma lógica que se fundamenta na transmissão de conhecimentos por um professor, que sabe, aos alunos, que não sabem. Essa foi, e ainda é, a lógica que fundamenta a crença inquestionável de que "quem sabe, automaticamente sabe ensinar", como assevera Masetto (2003), porque passou pelos bancos escolares e se consolidou como reconhecido profissional. Assim, essa lógica reafirma a ideia de que não é necessária a apropriação dos constructos epistemológicos e pedagógicos da profissão docente pelo professor. 
Pesquisas recentes no campo da pedagogia universitária têm buscado a conscientização, no universo acadêmico, de que a docência exige capacitação própria, porque exige um exercício de competências específicas, que não estão restritas à obtenção de um diploma ou título. A docência é, segundo Masetto (1998), uma profissão que demanda competências próprias, as quais são alicerçadas por saberes próprios da docência.

Os saberes da docência correspondem ao conjunto de conhecimentos, habilidades, competências e percepções que compõem a capacitação do sujeito para a atividade profissional da docência (Xavier, 2014); são plurais e heterogêneos, constituídos processualmente na existência das pessoas, como concluem os estudos de Tardif (2000). São todos os saberes construídos pelos professores nos diferentes espaços, de vida e de atuação, e que são acionados nos espaços cotidianos da docência. Por isso, nas palavras de Cunha (2006), os saberes da docência são caracterizados como experienciais, acadêmicos, profissionais, curriculares, disciplinares.

O domínio dos saberes docentes alicerça a prática pedagógica do professor, sendo esta, no contexto universitário, entendida como uma ação que envolve todas as atividades que permeiam a docência, na missão de indissociabilizar ensino, pesquisa e extensão. De tal forma, refere-se a todas as ações pedagógicas do exercício da docência. Amparada pela concepção defendida por Cunha (2010a), a prática pedagógica docente alicerçada em saberes próprios da docência se caracteriza como uma prática intencional, que se ocupa da produção do conhecimento e da cultura e que não se reduz à questão didática ou às metodologias de ensinar e de aprender.

Não obstante, embora fundamentais para o exercício da docência, os saberes, com exceção daqueles relacionados ao conteúdo específico da área de formação do professor e das disciplinas que leciona, foram compreendidos historicamente na universidade como desnecessários. Como consequência, a formação dos docentes universitários nesse rol de saberes, ainda hoje, não é valorizada. Assim, se entendemos por habitus (Bourdieu, 1994) a matriz de princípios que predispõe o sujeito a agir de uma maneira predeterminada, mediante analogias e com disposição estável, como aponta Cunha (2008), esse descompromisso com os saberes docentes contribui para que a formação do professor universitário se componha como um habitus carregado de conservadorismo. A prática pedagógica docente é, portanto, um modelo que foi e assume, ainda hoje, a transmissão e a reprodução de conhecimentos como dois dos seus pilares.

O que se conclui é que os conhecimentos pedagógicos, que compõem os saberes docentes, foram colocados em posição de desprivilégio na formação do professor universitário, conforme afirma Cunha (2008). Com isso, a ideia de que o bom modelo de ensino é baseado unicamente na transmissão e reprodução científica, com sobreposição às questões didático-pedagógicas, enraíza-se na universidade.

Nessa lógica, Morgado (2009) indica que o modelo de ensino baseado na transmissão dos conhecimentos científicos se perpetuou no tempo e contribuiu para que a reflexão pedagógica e o ensino crítico não se tornassem práticas da profissão docente. 
É nesse contexto, situado e historicamente construído, que emerge a preocupação com a formação pedagógica institucional do professor universitário, como elemento basilar do desenvolvimento profissional docente.

\section{Desenvolvimento profissional docente: conceito}

Vaillant (2009) defende a concepção de desenvolvimento profissional docente como formação profissional que remete a um ato contínuo ao longo da vida. Além da formação, o desenvolvimento profissional docente também envolve a profissionalização, "estabelecendo entre esses componentes uma relação dialética" (Leitinho, 2012, p. 134).

Nessa linha, o conceito de desenvolvimento profissional a orientar o programa de formação docente das instituições deverá ser o que propõe Carlos Garcia, isto é, "um processo que se vai construindo à medida que os docentes ganham experiência, sabedoria e consciência profissional" (Garcia, 2009, p. 11). Ainda segundo o autor, o desenvolvimento profissional docente é um processo "no qual se integram diferentes tipos de oportunidades e experiências, planificadas sistematicamente para promover o crescimento e desenvolvimento do docente" (Garcia, 2009, p. 7).

Na mesma direção, Imbernón (1998, p. 45) se refere ao desenvolvimento profissional docente como "uma atitude de constante aprendizagem por parte do professorado". Desse modo, a formação pedagógica docente, entendida como parte integrante do desenvolvimento profissional, define-se como um processo permanente de construção coletiva que renova a cultura profissional (Leitinho, 2012).

Fernandes, Bastos e Selbach (2010) argumentam que a formação pedagógica ocorre quando há a desinstalação, a insatisfação e o desequilíbrio com a racionalidade única do paradigma dominante - a competência técnicocientífica reconhecida e legitimada pelos pares -, o que estimula e conduz o professor a procurar alternativas para sua prática, seu trabalho. Assim posto, lembra Leitinho (2012) que a questão não se centra unicamente em atitudes constantes de aprendizagem por parte dos docentes, nem em intencionalidades isoladas, mas se vincula ao contexto político que se estabelece nas instituições de ensino universitário. Essas relações políticas contribuem para facilitar ou dificultar a institucionalização de programas de desenvolvimento profissional e, consequentemente, de formação pedagógica docente. Nesse sentido, a formação pedagógica pode, portanto, ser estimulada por meio de programas que unam essas intencionalidades (desenvolvimento profissional e formação pedagógica), de forma que se propicie ao corpo docente em formação oportunidades de aprimoramento e atualização.

Responsabilidade institucional: a quem compete a oferta de programas de desenvolvimento profissional docente?

Pensar a oferta de formação pedagógica com vistas ao desenvolvimento profissional docente, de acordo com a literatura aqui utilizada, requer pensar 
em institucionalização das ações. Nesse propósito, cabe o questionamento sobre a quem recai a responsabilidade institucional pela oferta de tais ações.

Tomamos a definição de institucionalização defendida por Xavier (2014) para tratar essa questão. A institucionalização, nesses casos, adota o sentido de promoção e valorização, em níveis institucionais, de espaços coletivos de formação. Essa institucionalização não se refere à imposição vertical de órgãos da instituição; pelo contrário, origina-se na construção horizontal de espaços formativos, que são coletivos e que, por tais características, transformam-se em lugares de formação. Nesses termos, a institucionalização é percebida como resposta às iniciativas individuais dos docentes, no sentido de estabelecerem práticas inovadoras, que fazem rupturas com as formas tradicionais de ensinar e aprender.

Cunha (2010b, p. 34) afirma "que o fato da formação do professor universitário ser realizada em múltiplos lugares, em diferentes modalidades e formatos, revela o seu 'não lugar', isto é, a escassa legitimidade dos lugares existentes". É, portanto, nesse cenário que se devem apresentar as Assessorias Pedagógicas Universitárias, como espaços próprios para o desenvolvimento da formação pedagógica do docente.

Broilo (2015) conceitua a Assessoria Pedagógica Universitária como o setor pedagógico que se preocupa em trabalhar grandes questões educativas, como forma de relacionar o ato pedagógico com o universo social dos professores, porque a ação pedagógica deve estar sempre vinculada ao modelo de sociedade em que se vive. Trata-se, portanto, de um setor que institucionalmente representa a formação pedagógica do docente, dentre um rol de atividades referentes ao ensinar e ao aprender na universidade. "A assessoria pedagógica universitária [...] é reconhecida como uma profissão de ajuda em um meio onde as práticas de intervenção se orientam a obter mudanças que afetam a instituição educativa como um todo e a aula em particular" (Lucarelli, 2008, p. 4).

A Assessoria Pedagógica precisa, então, ser um espaço legitimado institucionalmente. Entretanto, há que se considerar, nesse ínterim, que "a existência do espaço, sendo sempre potencial, abriga a possibilidade da existência de programas de formação docente, mas não a sua efetivação" (Cunha, 2010b, p. 53). Para que essa legitimidade seja alcançada, o espaço de formação precisa se constituir, segundo orienta Cunha (2010b), como um lugar, isto é, constituir-se com base em sentidos dados a esses espaços, na dimensão humana envolvida no processo de formação.

\section{Institucionalização de um programa de desenvolvimento profissional docente: histórico de um caso}

Do ponto de vista metodológico, esse estudo adotou uma abordagem qualitativa. Segundo Ludke e André (1986, p. 11-12), "a pesquisa qualitativa tem o ambiente natural como sua fonte direta e o pesquisador como seu principal instrumento". 
Bogdan e Biklen (2006) destacam como características básicas da pesquisa qualitativa: a fonte direta de dados é o ambiente natural e o investigador o instrumento principal; é primordialmente descritiva; há maior interesse pelo processo do que, simplesmente, pelos resultados ou produtos; a análise tende a ser feita de forma indutiva; o significado que os participantes dão aos objetos é de vital importância.

Foram utilizados, como procedimentos de coleta de dados, a análise documental (do Plano de Desenvolvimento Institucional - PDI -, da resolução que institui o programa e suas diversas alterações) e a aplicação de questionário estruturado aos professores que participaram do programa de formação.

Com base na literatura apresentada, analisamos a institucionalização de um programa de desenvolvimento profissional da Universidade Federal de Alfenas (Unifal-MG), com vistas a identificar seu nível de consolidação, bem como a concepção dos docentes sobre ele. A instituição foi fundada em 1914 e transformada em universidade em 2005, quando foi proposto o primeiro programa de formação para seus docentes.

Antes de sua transformação em universidade, os cursos oferecidos eram restritos à área de saúde (quatro cursos). Após poucos anos de sua transformação, a instituição demonstrou rápido crescimento, contando atualmente com quatro campi, 33 cursos de graduação e 18 programas de pós-graduação, com 22 cursos (16 mestrados acadêmicos, 2 mestrados profissionais e 4 doutorados). A instituição tem, portanto, uma história peculiar, pois é centenária, mas jovem enquanto universidade.

Segundo dados do Plano de Desenvolvimento Institucional (PDI) 20162020, a universidade possuía, em junho de 2015, 485 docentes efetivos, dos quais 385 com titulação de doutor. No documento, a previsão para 2016 era que o total de docentes chegasse a 495, sendo 409 doutores. No entanto, esse quantitativo já foi superado, pois a instituição encerrou o ano de 2015 com 497 docentes efetivos. No período de 2016 a 2020, está prevista a contratação de 41 novos docentes por meio de vagas já autorizadas.

Após a transformação da instituição em universidade, foi aprovado o Programa de Capacitação Pedagógica para Docentes, em agosto de 2005, pela Resolução no 10/2005 do Conselho de Pesquisa, Ensino e Extensão (Cepe). O objetivo do programa, declarado na Resolução, era "propiciar aos docentes [...] oportunidades de aprimoramento e de melhoria do processo ensino-aprendizagem e da prática docente" (Unifal-MG, 2005). Previa a participação tanto dos professores ingressantes quanto dos estáveis, que já faziam parte do corpo docente da instituição. No entanto, percebe-se, ao longo do documento, o foco no professor ingressante que ainda está cumprindo o estágio probatório.

O programa de formação era composto por duas ações: apresentação da estrutura acadêmica e administrativa da instituição, com duração de 8 horas, "visando promover a ambientação do professor ao local e às condições de trabalho, facilitar sua integração aos demais servidores e nortear sua vida funcional junto à instituição" (Unifal-MG, 2005); e o curso Metodologia e Didática de Ensino Superior, com carga horária de 30 horas, que deveria contemplar os 
[...] elementos pedagógicos indispensáveis ao exercício da carreira de docente de ensino superior, destacando aspectos que aprimorem o processo ensino-aprendizagem e permitam a elevação do padrão de qualidade do ensino praticado nos cursos e programas oferecidos. (Unifal-MG, 2005).

A participação nas duas atividades era requisito para aprovação no estágio probatório. A Resolução previa também a participação dos docentes estáveis, a cada ano, em parte do programa do curso Metodologia e Didática de Ensino Superior, sem clarificar como se daria esse processo. Efetivamente, a participação dos docentes estáveis não aconteceu.

Nessa primeira Resolução, que se concentra no período de estágio probatório e no cumprimento de uma carga horária determinada e baixa, identifica-se uma concepção de pedagogia universitária instrumental, "entendida como um conjunto de normas e prescrições" (Cunha, 2004, p. 526) que transformarão o profissional oriundo de diferentes áreas em um docente do ensino superior, apto a lidar com os desafios da universidade.

Em 2008, foram aprovadas as Resoluções $n^{\circ} 12 / 2008$ e no 13/2008, separando o programa de formação permanente dos docentes estáveis e o programa de formação para os docentes ingressantes. A Resolução $n^{0}$ 13/2008 tratava da formação dos professores estáveis por meio do Programa de Capacitação Pedagógica Permanente, que tinha como objetivo: "introduzir por meio de oficinas práticas didático-pedagógicas inovadoras, que somadas aos conhecimentos adquiridos durante a formação, produzirão resultados positivos em relação ao processo educacional" (Unifal-MG, 2008). Essa proposta não se efetivou.

Já a Resolução no 12/2008 abordava exclusivamente o Programa de Capacitação Pedagógica para Docentes em Estágio Probatório, com a finalidade de "propiciar aos docentes ingressantes [...] oportunidades de aprimoramento e de melhoria do processo ensino-aprendizagem e da prática docente" (Unifal-MG, 2008). Não houve mudanças, em relação à Resolução no 10/2005, no que se refere à estrutura do programa. Ele continuou sendo organizado em um curso de apresentação da estrutura acadêmica e administrativa, tendo sido alterada sua carga horária de 8 para 4 horas, e um curso de Metodologia e Didática do Ensino Superior, com alteração da carga horária de 30 para 90 horas.

No curso Metodologia e Didática do Ensino Superior, foram incluídos temas que permitiriam "uma ampla visão da realidade da instituição destacando a explanação de sua estrutura, seus objetivos, programas e planos de ensino" (Unifal-MG, 2008), além do objetivo já presente na Resolução $n^{\circ}$ 10/2005. Nota-se que o curso aumentou sua carga horária, mas incluiu temas de caráter administrativo ou burocrático, como preenchimento de programas e planos de ensino no sistema acadêmico e organização da instituição.

Retomando o histórico constitutivo do programa de desenvolvimento profissional da instituição, revela-se que as duas resoluções aprovadas em 2008 tiveram a preocupação de fomentar a participação dos professores estáveis no programa de formação. Essa preocupação explica-se, em muito, 
pela história da instituição, que manteve em seu quadro muitos professores que atuavam havia vários anos, mas em uma realidade institucional e de alunado diferente. No entanto, as resoluções fizeram uma distinção entre professores experientes e ingressantes, criando dois programas diferentes.

Em 2011, foi aprovada a Resolução no 9/2011, que revogou integralmente as Resoluções $n^{0} 12 / 2008$ e $n^{0} 13 / 2008$. Na resolução de 2011, o Programa Permanente de Desenvolvimento Profissional e Formação Pedagógica de Docentes volta a dirigir-se aos docentes da instituição sem distinção entre estáveis e ingressantes.

Há mudanças nessa nova proposta. O programa passa a ser dividido em quatro dimensões: I - Organização e gestão da estrutura acadêmicoadministrativa da instituição; II - Fundamentos educacionais do ensino superior; III - Bases epistemológicas, sociais e culturais do desenvolvimento no ensino superior; IV - Recursos, inovações e metodologias educacionais do ensino superior. O professor ingressante deveria cumprir 60 horas ao longo dos três anos de estágio probatório, sendo, pelo menos, 20 horas cumpridas na dimensão I. Das 40 restantes, o professor poderia utilizar até 20 horas em congressos, seminários e outros eventos dos quais tenha participado fora do programa.

Essas alterações demonstram uma preocupação maior com as questões práticas e/ou burocráticas, ou seja, funcionamento da carreira no que se refere aos critérios e procedimentos para progressão, funcionamento dos sistemas administrativos e acadêmicos, quando comparadas às questões pedagógicas e metodológicas. Tal postura corrobora a ideia de que "quem sabe, sabe ensinar", segundo a qual o professor acredita que, por ter a titulação exigida e ser aprovado em um concurso, saberá "dar aulas". Em geral, essas aulas se baseiam na reprodução daquilo que o docente viveu enquanto aluno.

Consideramos que houve avanços em relação às resoluções de 2008, pois o programa volta a ser tratado como formação docente para todos os professores da instituição, embora permaneça a ênfase no caráter de formação para os ingressantes, tratando quase exclusivamente das exigências para o estágio probatório. Outro progresso consistiu em contemplar novas dimensões da formação docente, tornando possível a participação de outras instâncias da universidade, além da Pró-Reitoria de Graduação.

É possível constatar o aumento da carga horária destinada a questões relativas à organização e gestão da estrutura acadêmicoadministrativa da instituição (dimensão I) que, na Resolução no 12/2008, era de 4 horas e, em 2011, passa a ter 20 horas obrigatórias. Por outro lado, as dimensões que contemplam fundamentos da educação, metodologias, bases epistemológicas, sociais e culturais, além de recursos e inovações para o ensino superior, antes contempladas no curso Metodologia e Didática de Ensino Superior, que tinha 90 horas, passam a ser abordadas em atividades que somam 40 horas, das quais 20 podem ser abatidas mediante outras atividades e eventos de que o professor participar. 
Em 2015, foram aprovadas alterações na resolução que regula o programa, que tiveram como objetivo principal fomentar a participação e responsabilização de outras Pró-Reitorias. Essa Resolução reforça, no Parágrafo Único do Art. $1^{\circ}$, a identificação do programa como exigência para a aprovação no estágio probatório, visto que "constitui-se na ação institucional de recepção e integração dos docentes ingressantes [...] a qual se refere o artigo 24 da Lei no 12.772/2012" (Unifal-MG, 2015a).

\section{Desafios da institucionalização da formação pedagógica docente: análise dos dados de pesquisa}

O docente que atua no ensino superior tem como especificidade profissional o fato de ter constituído sua identidade profissional vinculada à sua área de formação, sem conscientizar-se, muitas vezes, da importância de se apropriar de competências próprias ao seu fazer docente (Masetto, 1998; Cunha, 2004).

Nesse cenário, as dificuldades encontradas mesmo nos casos em que há tentativas de institucionalização da formação pedagógica são grandes, porque, ainda que haja espaços institucionais para garantir essa formação, eles enfrentam resistências para se transformarem em lugares, o que significa conseguir legitimação com base nos sentidos dados a esses espaços.

Em todo seu histórico, desde seu início em 2005, podemos afirmar que os maiores desafios do programa continuam sendo a participação dos docentes estáveis, que já cumpriram o estágio probatório, e a criação de uma cultura institucional de valorização da formação permanente do professor do ensino superior. No ano de 2015, dos 497 docentes efetivos da instituição, 217 participaram de pelo menos uma atividade do programa, o que representa, aproximadamente, $44 \%$ de participação. No entanto, se desse total considerarmos apenas os docentes estáveis, isto é, aqueles que já passaram pelo período de estágio probatório, verificamos que a participação corresponde a aproximadamente 32\% (70 docentes estáveis). Convém destacar que a participação maciça dos estáveis ocorreu em uma atividade cujo tema foi a redação científica, temática ligada à atuação do docente como pesquisador, o que reforça as teorizações aqui apontadas, no que tange à valorização dos saberes da área específica de atuação do professor, em detrimento dos saberes próprios da docência.

Esse número nos leva a refletir sobre a efetividade da participação dos docentes, quando não estão submetidos a normas e regulações. Parece ser evidente que a maior participação se dá entre os que estão em período de estágio probatório, obrigados a cumprir uma exigência legal. O índice de participação parece demonstrar que a preocupação com a formação pedagógica permanente, fundamental para o exercício pleno da docência, não representa uma prioridade para o público analisado.

Assim como tratado por Leitinho (2012), a questão política, que se estabelece nas instituições de ensino universitário e contribui para facilitar a institucionalização de programas de desenvolvimento profissional 
e consequente formação pedagógica docente, ainda não parece ser uma realidade consolidada. Afora isso, é necessário questionar se os espaços de formação e as políticas instituídas são transpostos para lugares de formação. Parece fundamental referendar que sem a legitimidade devida às Assessorias Pedagógicas Universitárias, conquistadas mediante tal transposição, a efetivação da formação pedagógica docente ficará sempre à mercê de atos regulatórios que obriguem a participação dos professores.

Ao analisar as atividades ofertadas no programa de formação aqui discutido, no segundo semestre de 2015, verifica-se maior interesse docente nas questões ligadas aos aspectos práticos e/ou burocráticos da docência (uso de sistemas acadêmicos, trâmites legais), como já mencionado, do que no conhecimento específico para o ensino. Nas avaliações que os docentes preencheram durante as atividades desse período, a maioria das temáticas consideradas de interesse para realização de atividades dentro do programa estão ligadas a esses aspectos práticos e burocráticos.

As temáticas de interesse apontadas pelos docentes, no segundo semestre de 2015, foram:

- Programas de tutoria (aplicação prática; dificuldades encontradas; estratégias de tutoria; avaliação de tutoria).

- Transição da vida escolar para a vida acadêmica.

- Apresentação da instituição a docentes ingressantes.

- Diário de frequência.

- Plano de aula e programa de ensino.

- Discussão sobre o sistema acadêmico.

- Progressão na carreira.

- Administração do tempo.

- Gestão de projetos.

- Concepção de ensino-aprendizagem.

- Metodologias ativas de ensino.

- Avaliação.

- Estratégias de motivação dos alunos.

Das 13 temáticas apresentadas, 7 (que estão destacadas) relacionam-se ao funcionamento administrativo da instituição e das atribuições docentes. Destaca-se que as duas primeiras apareceram, provavelmente, porque a instituição discutia, no momento da coleta e análise dos dados, a implementação de um programa de tutoria e acolhimento de alunos ingressantes, proposto pela equipe técnica da Pró-Reitoria de Graduação, e não porque seja um tema trazido pelos próprios docentes.

Essas indicações reforçam a posição subalterna do saber docente, sendo, portanto, evidências diárias no cotidiano da docência universitária. Essa assertiva é reforçada pelo fato de que a dedicação dos profissionais da docência para as questões pedagógicas e humanísticas do ensino não são valorizadas na mesma intensidade como são os conhecimentos e conteúdos específicos que ministram. 
Cunha (2009b) afirma que o fato realmente interessante para o professor universitário é o domínio do conhecimento da área na qual se especializou, de forma que este se prepara e busca excelência nas atividades de pesquisa. Alia-se a essa realidade a preocupação com as questões administrativas da instituição, também em sobreposição à formação pedagógica para a docência. Essa condição parece reforçar o desprestígio da formação pedagógica docente, afirmada pela lógica de recrutamento de professores no ensino superior. Ainda hoje, essa lógica se embasa na ideia de que "quem sabe fazer sabe ensinar" (Cunha, 2009a; Masetto, 2003). Então, "o próprio ingresso na carreira universitária revela que não há uma preocupação com a formação pedagógica do professor universitário" (Fernandes; Bastos; Selbach, 2010, p. 126).

\section{Algumas considerações}

Com base nas concepções de desenvolvimento profissional docente apresentadas e na realidade que circunda a formação pedagógica para a docência, torna-se necessário não apenas propor ações que fomentem maior participação dos docentes estáveis, mas também elaborar documentos institucionais que favoreçam essa participação, diferentes das resoluções adotadas até agora na instituição.

Os documentos institucionais analisados reforçam a visão do programa de formação docente como uma exigência legal para aprovação no estágio probatório, destinado, dessa forma, aos professores ingressantes. Entretanto, entendemos que os documentos institucionais deveriam demonstrar que o programa se apoia em uma concepção de formação docente enquanto "um processo que se vai construindo à medida que os docentes ganham experiência, sabedoria e consciência profissional" (Garcia, 2009, p. 11) e "uma atitude de constante aprendizagem por parte do professorado" (Imbernón, 1998, p. 45), em que o cumprimento da exigência para aprovação no estágio probatório seja apenas um apêndice, bem diferente do que se adota atualmente.

Considerando, assim, a essencialidade que o desenvolvimento profissional docente representa para o processo de ensinar e de aprender, para a constituição da profissionalidade e identidade docente e para a promoção de oportunidades de superação das dificuldades vivenciadas nas ações objetivas da prática pedagógica, os programas de desenvolvimento profissional devem ser concebidos de maneira institucional, revelando a intencionalidade e o compromisso com a formação docente, assumidos como percursos permanentes de aprimoramento formativo (Xavier, 2014). É necessário configurar a formação pedagógica "como um construto teórico-prático marcado pela intencionalidade de um projeto de ação transformadora e emancipatória que tem na sua dimensão coletiva e na responsabilidade institucional uma possibilidade de concretude" (Fernandes; Bastos; Selbach, 2010, p. 133). 
O construto teórico-prático se constitui dos saberes da prática e da teoria, que nascem da reflexão, e permite a criação de redes com as várias epistemologias de outras áreas, não somente as humanas. É assumida a responsabilidade com o percurso de aprimoramento formativo, em busca da concretude e definição da profissionalidade e identidade docente.

Toda essa reflexão nos direciona a alguns questionamentos, já apontados por Xavier (2014): Não seria uma incoerência delimitar uma carga horária mínima a ser cumprida, pois essa ação levaria à inferência de que é possível se quantificar a participação em espaços de formação? Não reforçaria, com isso, a ideia de que é possível delimitar o início e o fim da formação docente, quantificada em horas, indo, portanto, contra a concepção de formação contínua ao longo da carreira? Ora, se são esses espaços que conduzem à reflexão e à construção de novos saberes, por que a obrigatoriedade de estipular uma carga horária mínima de participação?

Enfim, não podemos desconsiderar que a experiência analisada retrata um programa de formação pedagógica e de desenvolvimento profissional docente relativamente jovem, com apenas dez anos de existência. Assim, frente às alterações que o programa já experimentou, pode-se inferir que há uma preocupação em aprimorá-lo. Somente por meio dessa preocupação com a formação pedagógica serão construídos espaços que poderão se transformar em lugares de formação.

\section{Referências bibliográficas}

BOGDAN, R.; BIKLEN, S. Investigação qualitativa em educação: uma introdução à teoria e aos métodos. Porto: Porto Editora, 2006.

BOURDIEU, P. O campo científico. In: ORTIZ, R. (Org.). Pierre Bourdieu: sociologia. São Paulo: Atica, 1994. p. 122-155.

BROILO, C. L. Assessoria pedagógica na universidade: (con)formando o trabalho docente. Araraquara: Junqueira \& Marin, 2015.

CUNHA, M. I. Diferentes olhares sobre as práticas pedagógicas no ensino superior: a docência e sua formação. Educação, Porto Alegre, v. 27, n. 3, p. 525-536, set./dez. 2004.

CUNHA, M. I. Docência na universidade, cultura e avaliação institucional: saberes silenciados em questão. Revista Brasileira de Educação, Rio de Janeiro, v. 11, n. 32, p. 258-271, maio/ago. 2006.

CUNHA, M. I. Inovações pedagógicas: o desafio da reconfiguração de saberes na docência universitária. São Paulo: Ed. da USP, 2008. (Cadernos Pedagogia Universitária, 6). 
CUNHA, M. I. Inovações pedagógicas: o desafio da reconfiguração de saberes na docência universitária. In: PIMENTA, S. G.; ALMEIDA, M. I. (Orgs.). Pedagogia universitária. São Paulo: Ed. da USP, 2009a. p. 211-236.

CUNHA, M. I. Inovações pedagógicas na universidade. In: CUNHA, M. I.; SOARES, S. R.; RIBEIRO, M. L. (Orgs.). Docência universitária: profissionalização e prática educativa. Feira de Santana: Ed. da UEFS, 2009b. p. 169-190.

CUNHA, M. I. Indicadores de qualidade e a relação do ensino com a pesquisa e a extensão na universidade brasileira. In: COLOQUIO INTERNACIONAL SOBRE GESTIÓN UNIVERSITARIA EM AMÉRICA DEL SUR, 10., 2010, Mar del Plata. Actas... Mar del Plata: UNMdP, 2010a.

CUNHA, M. I. (Org.). Trajetórias e lugares da formação da docência universitária: da perspectiva individual ao espaço institucional. Araraquara: Junqueira \& Marin, 2010b.

FERNANDES, C. M. B.; BASTOS, A. R. B.; SELBACH, P. T. S. Cursos e disciplinas de formação pedagógica do professor universitário: movimentos em aberto. In: CUNHA, M. I. (Org.). Trajetórias e lugares de formação da docência universitária: da perspectiva individual ao espaço institucional. Araraquara: Junqueira \& Marin; Brasília: CAPES/ CNPq, 2010. p. 125-145.

GARCIA, C. M. Desenvolvimento profissional docente: passado e futuro. Sísifo: Revista de Ciências da Educação, Lisboa, n. 8, p. 7-22, 2009.

IMBERNÓN, F. La formación y el desarrollo profesional del profesorado. Barcelona: Graão, 1998.

LEITINHO, M. C. Política de desenvolvimento profissional docente: fundamentos e práticas. In: D’ÁVILA, C.; VEIGA, I. P. A. (Orgs.). Didática e docência na educação superior: implicações para a formação de professores. Campinas: Papirus, 2012. p. 133-146.

LUCARELLI, E. Asesoria pedagógica y cambio en la universidad. Profesorado: Revista de Curriculum y Formación del Professorado, Granada, v. 12, n. 1, p. 1-14, 2008.

LÜDKE, M.; ANDRÉ, M. E. D. A. Pesquisa em educação: abordagens qualitativas. São Paulo: EPU, 1986.

MASETTO, M. T. Professor universitário: um profissional da educação na atividade docente. In: MASETTO, M. T. (Org.). Docência na universidade. Campinas: Papirus, 1998. p. 9-25. 
MASETTO, M. T. Competência pedagógica do professor universitário. São Paulo: Summus, 2003.

MORGADO, J. C. Processo de Bolonha e ensino superior num mundo globalizado. Educação \& Sociedade, Campinas, v. 30, n. 106, p. 37-62, jan./abr. 2009.

TARDIF, M. Saberes profissionais dos professores e conhecimentos universitários: elementos para uma epistemologia da prática profissional dos professores e suas consequências em relação à formação para o magistério. Revista Brasileira de Educação, Rio de Janeiro, n. 13, p. 5-24, jan./abr. 2000.

UNIVERSIDADE FEDERAL DE ALFENAS (Unifal-MG). Conselho de Ensino, Pesquisa e Extensão. Resolução no 10, de 17 de agosto de 2005. Aprova o programa de capacitação pedagógica para docentes da Unifal - MG. Alfenas, 2005. Disponível em: <http://www.unifal-mg.edu.br/ secretariageral/files/file/CEPE/2005/Res10CEPE2005.pdf >.

UNIVERSIDADE FEDERAL DE ALFENAS (Unifal-MG). Conselho de Ensino, Pesquisa e Extensão. Resolução no 12, de 22 de outubro de 2008. Dispõe sobre o programa de capacitação pedagógica para docentes em estágio probatório da Universidade Federal de Alfenas Unifal/MG. Alfenas, 2008. Disponível em: <http://www.unifal-mg.edu. br/secretariageral/files/file/CEPE/2008/Res12CEPE2008.pdf >.

UNIVERSIDADE FEDERAL DE ALFENAS (Unifal-MG). Conselho de Ensino, Pesquisa e Extensão. Resolução no 13, de 22 de outubro de 2008. Dispõe sobre o programa de capacitação pedagógica permanente para docentes da Universidade Federal de Alfenas - Unifal/MG. Alfenas, 2008. Disponível em: <http://www.unifal-mg.edu.br/secretariageral/files/file/ CEPE/2008/Res13CEPE2008.pdf>.

UNIVERSIDADE FEDERAL DE ALFENAS (Unifal-MG). Conselho de Ensino, Pesquisa e Extensão. Resolução no 9, de 18 de maio de 2011. Dispõe sobre o programa permanente de desenvolvimento profissional e formação pedagógica de docentes da Universidade Federal de Alfenas - Unifal- MG. Alfenas, 2011. Disponível em: <http://www.unifal-mg.edu. br/secretariageral/files/file/CEPE/2011/Resolucao_009-2011_CEPE.pdf >.

UNIVERSIDADE FEDERAL DE ALFENAS (Unifal-MG). Conselho de Ensino, Pesquisa e Extensão. Resolução $n^{\circ} 29$, de 23 de novembro de 2015. Dispõe sobre o programa permanente de desenvolvimento profissional e formação pedagógica de docentes da Universidade Federal de Alfenas. Alfenas, 2015a. Disponível em: <http://www.unifal-mg.edu. br/secretariageral/files/file/CEPE/2015/Resolucao_029-2015.pdf >. 
UNIVERSIDADE FEDERAL DE ALFENAS (Unifal-MG). Plano de desenvolvimento institucional 2016 a 2020. Alfenas, 2015b. Disponível em: <http://www.unifal-mg.edu.br/planejamento/sites/default/files/ proplan/PDI\%20com\%20a\%20Resolu\%C3\%A7ao\%20e\%20com\%20 anexos.pdf $>$.

VAILLANT, D. Políticas para un desarrollo profesional docente efectivo. In: MEDRANO, C. V.; VAILLANT, D. Aprendizaje y desarrollo profesional docente. Madrid: OEI; Fundación Santillana, 2009. p. 29-38.

XAVIER, A. R. C. Universidade Nova: desafios para a prática pedagógica numa perspectiva interdisciplinar. Rio Claro: Ed. da Unesp, 2014.

Recebido em 11 de julho de 2016.

Solicitação de correções em 8 de novembro de 2016.

Aprovado em 22 de novembro de 2016. 